\title{
Modeling and analysis of mobile business processes
}

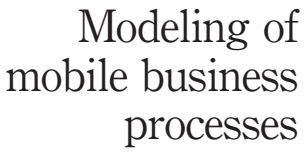

657

\author{
V. Gruhn and A. Köhler \\ University of Leipzig, Chair of Applied Telematics/e-Business, Leipzig, \\ Germany, and \\ R. Klawes \\ Deutsche Bank AG, Eschborn, Germany
}

\begin{abstract}
Purpose - The purpose of this paper is to present results from an analysis of service processes regarding their optimization potential through mobile technologies. The analysis was performed with a company of the housing industry.

Design/methodology/approach - The analysis was conducted with the aim of organizing business processes more efficiently in order to realize cost savings. Therefore, a method introduced in this paper was used.

Findings - It is shown how the initial situation of the company was analyzed, which alternative process models on the basis of mobile technologies were developed and how these alternatives were economically evaluated. Furthermore, first restrictions for the software and system design were identified on the basis of one process model. Finally, it is shown how the method can be used to verify whether the adoption of mobile technologies is suitable to obtain a defined goal, and which requirements such a solution needs to fulfill.

Originality/value - This paper shows practitioners how to conduct a systematic analysis of business processes regarding their optimization potential through mobile technologies.

Keywords Modelling, Communication technologies, Systems analysis, Optimization tehniques

Paper type Case study

\section{Introduction}

Since the availability of broadband radio networks and the reduced costs for mobile devices, the use of mobility-supporting technology has become an interesting opportunity for companies in order to optimize selected business processes for increased efficiency. Such mobile business processes can often be found in industries with a large field staff, e.g. for sales or service purposes. Amongst others, the insurance industry, housing industry, telecommunications industry, home care companies and maintenance companies belong to this group.

These companies' mobile business processes are often similar in the way that mobile employees often need to move from one point of service (POS) to another, where they need to access some data and produce some more data. Thus, a mobile business process is characterized by a high degree of mobility of the concerned employees and by a lack of knowledge about future locations they need to go to. An online connection to the company's backend systems is often desirable to provide staff with current data anywhere, anytime.
\end{abstract}

The authors would like to thank Matthias Book for his valuable comments on this article. The chair of Applied Telematics/e-Business is endowed by Deutsche Telekom AG.

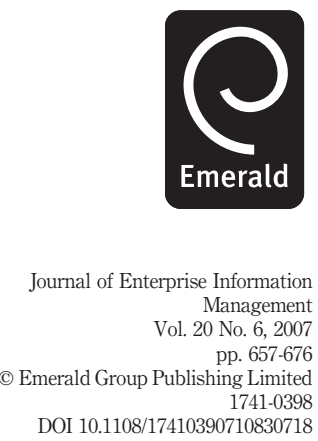


JEIM 20,6

658
Usually, such data are stored in central backend systems of the company. However, most mobile business processes are still paper-based today. The employee often prints out the necessary data before he starts his tour and afterwards enters the data collected at the POS from paper into the appropriate IT system. Such a process is typically characterized by cumbersome and error-prone format conversions, long processing times, lack of information regarding the actual location of an employee and the inability to access unanticipated data from the POS.

Aiming at reducing process costs, mobile technology can be used to overcome these shortcomings. While the paper-based process is on one end of the spectrum of solutions, the opposite scenario would be an always-online system with the employee using just a mobile device that can access the company's backend systems anytime via a mobile network. Such a solution very likely would avoid the above-mentioned shortcomings. On the other hand, an enormous investment would be needed to implement it. Between these two extremes of always-offline and always-online scenarios, many other solutions are conceivable. These would use different mobile technologies, e.g. devices that are only sometimes online to synchronize with the back end. In many cases, the needed investment for realizing such scenarios is lower than the always-online extreme, but grows with the capability of the mobile IT solution.

Hence, the main question that needs to be answered is how to choose a suitable mobile solution for achieving savings from reduced process costs that are as high as possible and exceed the initial investment after a certain period of time. Thus, a typical return on investment (ROI) analysis has to be carried out for a mobile project. In this paper it is shown how to obtain predictions for costs and benefits for a mobile IT solution, in particular how to conduct a process analysis for the current process. Furthermore, we show how to calculate execution costs of the target process, how to develop different mobile IT solutions and how to conduct an ROI analysis for the target scenarios.

This article is organized as follows: the next section contains a review of the related work. In the following section, the methodology used to solve the problem described above is explained. Afterwards, the use of this methodology is shown by a case study. In the final section, the conclusion is drawn.

\section{Literature review}

The concept of mobility is analyzed by Kakihara and Sorensen (2001). Usually, in the context of mobile applications and mobile workforces the term mobility is used in the meaning of spatial mobility. Kakihara and Sorensen expand this concept to temporal and contextual mobility. Amongst others, temporal mobility describes the fact that "it is no longer strictly necessary to share the same time period exclusively with a particular person or group" (Kakihara and Sorensen, 2001). In other words, the term describes the absence of temporal constraints through the use of mobile technologies. Beyond, contextual mobility is given when contextual constraints for a certain task of a mobile worker can be avoided, e.g. when he carries the necessary information to the place of task completion. This work gives an excellent analytical basis for further work on the mobility concept. The concept of mobility is also subject of Thai et al. (2003) where user mobility is distinguished into personal and terminal mobility. The paper gives an overview about recent developments on OSI network levels for improving terminal mobility, i.e. connectivity. Moreover, the authors present an integrated personal mobility architecture that supports personal mobility. This architecture aims at context preservation during device or network changes. On the basis of these key factors, 
concrete implications for the design of mobile systems in general are given. The particular importance of context is also subject of Dix et al. (2000). Different types of contexts in mobile environments like the infrastructure context, the system context, the domain context and the physical context are discussed. On this basis a design framework for mobile systems is presented that can be used to develop models of space and awareness and deduce requirements for software architectures from them. Perry et al. (2001) also present results regarding the basic concept of mobility. They present a study where different aspects of mobile work in general are examined. The four key factors identified for mobile work are the role of planning, working in dead time, accessing remote resources and monitoring distant activities. The changes for the discipline of software engineering when developing systems for mobile environments are discussed in Roman et al. (2000). They state that "mobility represents a total meltdown of all stability assumptions [...] associated with distributed computing." The authors give a comprehensive overview of software engineering for mobile systems, regarding issues like models, algorithms, applications and middleware to solve in the future.

As stated above, a number of recent publications show that efficiency and effectiveness of business processes can be improved through the use of mobile technologies. A case study shows examples for mobile business processes from Sweden and The Netherlands (van der Heijden and Valiente, 2002). After stating that benefits of mobile technology are hard to quantify, the authors deduce certain propositions from their case studies. The first proposition is that a benefit is given when coordination is required for actors how are difficult to locate. The second proposition is that the benefit of a mobile solution is the avoidance of opportunity costs that occur due to not being able to coordinate actors. However, to examine such opportunity costs will likely be difficult. Furthermore, there are more advantages in mobile solutions than just coordination of mobile actors, e.g. the avoidance of error-prone format conversions or just-in-time data supply. Bowden et al. (2004) also address the introduction of mobile systems in the construction industry with particular focus on the mapping of business processes. The presented methodology consists of the four steps identify ten processes, map out the as-is-process, map out the to-be-process, and select four processes. The method is evaluated with site engineer processes. This method works similar to the process mapping technique presented below, but it does not consider a limitation of the number of mapped processes. A business process analysis for the electricity industry is presented in Kavakli and Loucopoulos (1998). The authors show a method for identifying and modeling selected business processes for a certain goal. The method consists of a knowledge model, a goal submodel and a process submodel containing actors, roles, activities and resources. Based on these tools, the concrete goals and process models for a company can be created, followed by an analysis of these results. Another case study presents results from an analysis of mobile police work (Pica et al., 2004). The authors recommend to strongly focus on the type of mobility when dealing with mobile workers in order to design the right mode of interaction. Further, the distinction between structured and unstructured work is recommended when designing mobile systems.

The challenge of designing systems for mobile workplaces is subject of Churchill and Munro (2001). The authors distinguish between field workers who are mobile between fixed locations and workers who try to get work done in unpredictable locations with unknown infrastructure conditions. Based on this distinction, several aspects to be considered when designing mobile systems are pointed out. Sairamesh et al. (2004) provide a comprehensive collection of aspects to be considered when

\section{Modeling of mobile business \\ processes}

659 
JEIM
20,6

\section{0}

developing a software architecture for a mobile system. Amongst others, application states, connection models and synchronization aspects are discussed from a business process as well as from a technological point-of-view. The result of this discussion leads to an architecture model and a design criteria catalog. As stated above, a lot of work is done regarding system architectures and other technical aspects of mobile system. An example for this work is Dustdar and Gall (2003), where a three-layer software architecture for distributed and mobile collaboration is presented.

As shown above, the literature regarding mobile IT solutions can basically be divided into three parts (see Table I). First, research has been done regarding the general concept of mobility and its impact on the software engineering process. Second, a couple of case studies are available showing the advantages of mobile IT solutions within certain companies or industries. Third, within the technical perspective, research has been done in the field of software architectures and frameworks, wireless networks and mobile hardware. Unfortunately, between the latter two research areas, there is a lack of methodology describing the planning and the design of a mobile IT solution from a business analysis point-of-view.

Wang et al. (2005) report on a similar appraisal. They provide an analysis framework focusing on assessing the design approach of mobile workforce solutions. Within this analysis framework, the four perspectives thinking, controlling, working and modeling are distinguished. The thinking perspective includes engineering aspects like network infrastructures and middleware (called hard thinking), as well as communication aspects with involved actors and the mobile workforce (called soft thinking). The controlling perspective deals with the way the project and processes are managed. The working perspective describes how business engineers try to create solutions for the workforce problem, as well as the information system design. The modeling perspective consists of conceptual and empirical modeling of business processes and application prototyping. Although this framework contains certain important aspects for the modeling of mobile IT solutions, no details are given for conducting the mentioned steps from the four different perspectives. May et al. (2005) present an analysis of requirements for mobile systems within the construction industry. Starting from defined situations, the information needed on site, the information created on site and the involved people are identified. Furthermore, core business functions for specific problem situations are developed. This procedure complies with our method but does not address the issue of calculating the profitability

\begin{tabular}{ll}
\hline Category & Authors \\
\hline Analysis of mobility concept & $\begin{array}{l}\text { Kakihara and Sorensen (2001), Thai } \text { et al. (2003), Dix et al. (2000), Perry } \\
\text { et al. (2001), Roman } \text { et al. (2000) }\end{array}$ \\
Analysis of mobile processes & $\begin{array}{l}\text { van der Heijden and Valiente (2002), Bowden } \text { et al. (2004), Kavakli and } \\
\text { Loucopoulos (1998), Pica } \text { et al. (2004) }\end{array}$
\end{tabular}

Mobile system architectures Thai et al. (2003), Sairamesh et al. (2004), Dustdar and Gall (2003)

Planning of mobile systems Wang et al. (2005), May et al. (2005), Saleh and Alshawi (2005), Heemstra and Kusters (2004), Nah et al. (2005), Churchill and Munro (2001)

Table I.

Literature overview
Kohli et al. (2003), Kleist (2003), Leem et al. (2004) 
of the mobile solution. In Saleh and Alshawi (2005) a model for assessing the readiness prior to IS investment is described. Equally to the approach presented in this paper, the model starts from the business objectives. How to define ICT proposals is subject of Heemstra and Kusters (2004). This work could be helpful to systematically describe the proposed IT project after a first requirements analysis. Nah et al. (2005) present results from a case study with a utility company. On the basis of interviews with the company's employees, the authors developed a means-ends objective network that can be used to increase the value of a mobile application. There are six fundamental objectives a company tries to reach through the use of a mobile application. Beyond, there are numerous mean objectives that must be fulfilled in order to reach a fundamental objective. This work could be very helpful for achieving a company's objective by implementing mobile applications.

An interesting approach to a process-centered IT ROI analysis is described in Leem et al. (2004). The authors report a case study where an IT ROI is calculated for a business process from the banking industry. According to their experiences they propose a seven-phase model in order to calculate the ROI. Kleist (2003) proposes an approach to evaluate e-business information systems projects in order to calculate IT payoff. The approach focuses on traditional measures for IT payoff and their linkage to technology questions. The current research questions regarding IT investment payoff in e-business environments are raised in Kohli et al. (2003). The authors propose directions for future research in this field, namely metrics, environment, technology and process. The latter two are in the focus of this paper.

\section{Methodology}

Mobile business process definition

In the following, only business processes with a specific distribution structure and thus a certain mobility of the person executing the process are considered. It is supposed that mobility is given when an uncertainty of location for at least one activity exists. This assumption is based on the concept of location uncertainty by (van der Heijden and Valiente, 2002), according to which the place of execution of an activity can be different in different instances of the business process, or the place can change during the execution of an activity. Because multiple mobile activities are conceivable, and a mobile activity often affects the whole business process, the complete business process is called a mobile business process.

Furthermore, it can be noted that the uncertainty of location is externally determined. This assumption implies that location uncertainty is caused by external factors and that the process-executing person has therefore no freedom of choice regarding the place of the process execution. Beyond, cooperation with external resources (from the process point-of-view) is often needed during the execution of the process. This fact restricts a mobile business process to a process in which cooperation with external resources is necessary, for instance caused by the need for communication or coordination with other persons or interaction with other objects. Considering this, we propose the following definition: a mobile business process is a business process, in which:

(1) at least one person is involved, who executes their tasks in different locations;

(2) the actual location of task execution is known only vaguely and/or only shortly before the beginning of the task; and

\section{Modeling of mobile business \\ processes}

661 
JEIM

20,6

662

(3) this uncertainty (2) is determined externally and cannot be fully controlled by the task-executing person.

On the basis of this definition, two conclusions can be drawn. First, the definition implies that the assigned task causes the mobility of the involved person. The mobile worker needs to move physically to the specified location in order to interact with an entity (e.g. a damaged device or a customer) that is necessary for the completion of his task. Second, it is not relevant for this definition whether mobile information technology is used or not. In fact, mobile information technology will be the key for the realization of an efficient workflow in the majority of the cases.

\section{Aim and structure of the method}

The method proposed below aims at:

- discovering mobile processes in a business process model;

- analyzing potential for process optimization through supporting or eliminating mobile activities;

- developing alternative solutions based on the use of mobility-supporting technology;

- evaluating those alternatives economically; and

- deducing general conditions and requirements for the software and system design for the selected alternative.

The method was developed during different industry projects conducted at the University of Leipzig. Beyond, it is influenced by other approaches like May et al. (2005) and Nah et al. (2005). Figure 1 shows the essential steps of the method. First, the company needs to define the objective that is to be achieved by use of this method. Usually, the goal is to optimize the process parameter (personnel) costs, the duration of the process or the quality of the produced goods and services. As soon as the objective is defined one can start with describing the processes and depicting them as a process landscape. The process landscape shows relations between the main business processes and allows its user to recognize dependencies between processes very early. During the next step, the sub-processes characterized by a high degree of mobility of the process-executing person need to be identified. Therefore, the method provides an assessment scheme that is explained within the case study. If mobile processes are identified, an analysis is necessary.

During this step, shortcomings in the process flow resulting from the mobility of the process-executing person can be discovered. On the basis of these insights, new process versions can be developed in order to avoid the recognized shortcomings. This can be achieved by constraining or supporting the mobility within the process. Subsequently, the different alternatives need to be evaluated from an economic point of view. If a positive decision for the realization of one alternative has been reached, first requirements specifications and restrictions for the software architecture can be deduced.

Figure 1.

Steps of the method

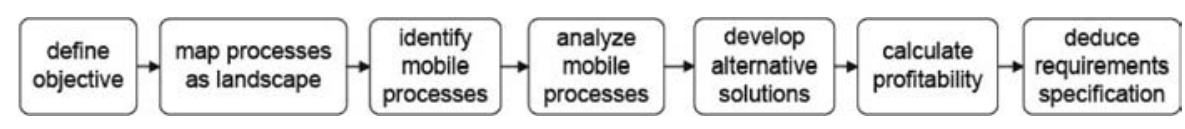


On the basis of these results, alternative solutions can be evaluated according to the company's strategic goals. The architecture of the resulting system can be developed on the foundation of clear, professional guidelines.

\section{Case study}

Introduction

In the following, the application of the method is shown by example of a municipal housing company located in a German city. Its main task is to assure a socially acceptable apartment supply for a great number of the 500,000 citizens. For this purpose, the company builds and maintains apartments particularly in the low price segment. These apartments are mainly located in multi-storey houses that are affected by vacancy more than averagely.

The economic situation in the concerned real estate market is characterized by a considerable oversupply of apartments. Because of the large share of vacant apartments (approx. 17 percent), as well as the continuous migration of prosperous inhabitants into the suburbs, landlords compete for the lowest rents on the market. In this situation, the company is confronted with high losses of revenue and high costs for maintenance. In order to overcome this situation, the company induced a variety of steps to lower the costs. In this context, an examination and analysis of the internal workflows was planned in order to discover potential for optimization. The company quickly focused on its maintenance processes because of the very large number of apartments (approx. 12,000) and therefore the very large number of process recurrences. Furthermore, these processes are characterized by a high degree of mobility of the process-executing person. These facts promised a high potential for optimization. Therefore, the company asked the University of Leipzig to conduct an analysis using the method introduced above. The precise proceedings of this project and the achieved results are presented in the following subsections that correspond to the structure of the method as illustrated in Figure 1.

\section{Defining the objective}

The company aimed at preferably high cost savings by an optimization of the business processes with a high degree of mobility of the process-executing person. The use of mobile technology therefore was favored. The analysis was to be conducted for the business process technical service. As a result, a couple of alternative technical and process solutions as well as an economical evaluation and first requirement specifications of those were expected.

\section{Mapping processes as a landscape}

The business process technical service consists of the sub-processes maintenance, administration, allocation of costs, billing and recording of consumption values. These business processes are depicted as a process landscape to recognize their essential relations to each other (Figure 2). The sub-processes are evaluated by the degree of added value and the assumed degree of mobility. The sub-processes Allocation of costs and administration were classified as slightly value-adding and not mobile. The sub-process billing was classified as value-adding but not mobile. The sub-process maintenance is extremely mobile but just slightly value-adding due to the fact that necessary repairs need to be achieved but no revenue can be gained from them. The sub-process recording of consumption values is extremely mobile and value adding.

\section{Modeling of mobile business \\ processes}




\section{JEIM \\ 20,6}

\section{4}

Figure 2.

Process landscape of the technical service process recording of consumption values

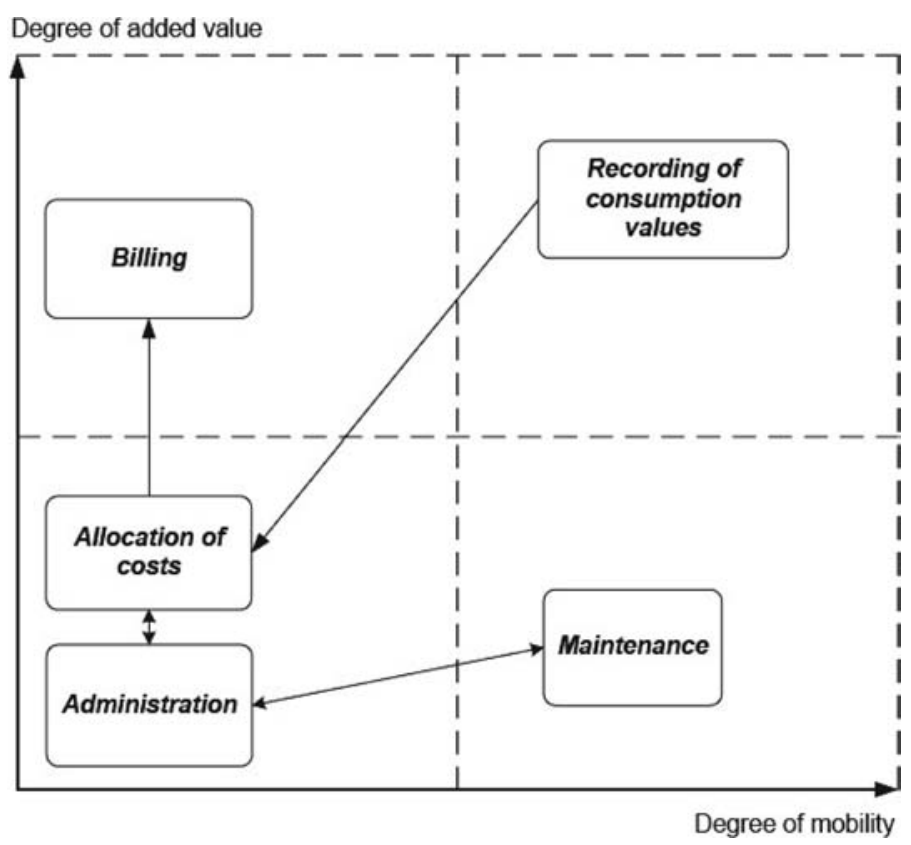

Because of this classification, the sub-process was examined in more detail. Figure 3 shows the detailed sub-process in the business process modeling notation (White, 2003).

The sub-process recording of consumption values contains the recording, transportation and processing of consumption values for water and heating. They are measured by appropriate meters for each apartment. The recording of the consumption values is performed by a subsidiary service company. The process starts when the service company is ordered to record the consumptions in all properties of the housing company. This is done once a year. The execution of the whole process takes three months for approximately 12,000 apartments in 240 properties. A property is a real estate that contains 50 apartments on average. The housing company sends lists with addresses and tenant data to the service company to prepare the recording of the consumption values. Subsequently, the service company processes the acquired lists electronically for the upcoming tasks (process data records in Figure 3). On the basis of this information, dates for the recording are arranged and efficient tours for the inspection of the apartments are planned (plan tour). Furthermore, for each daily tour, paper lists with addresses and tenant data are created. These preparing tasks take about one week.

After completing the tour planning, the service technicians are informed about their individual tours (inform service technicians). Afterwards, they drive to their assigned properties and attach an information sheet with the recording date to each entrance (provide information sheet). Shortly before the date of recording, the service technicians drive to the office to pick up recording lists as well as information about the recording procedure (brief service technician). Then, they drive to the properties according to their tour plans and start recording (meter-reading). For each apartment an average of four values need to be recorded. The service technician walks from 


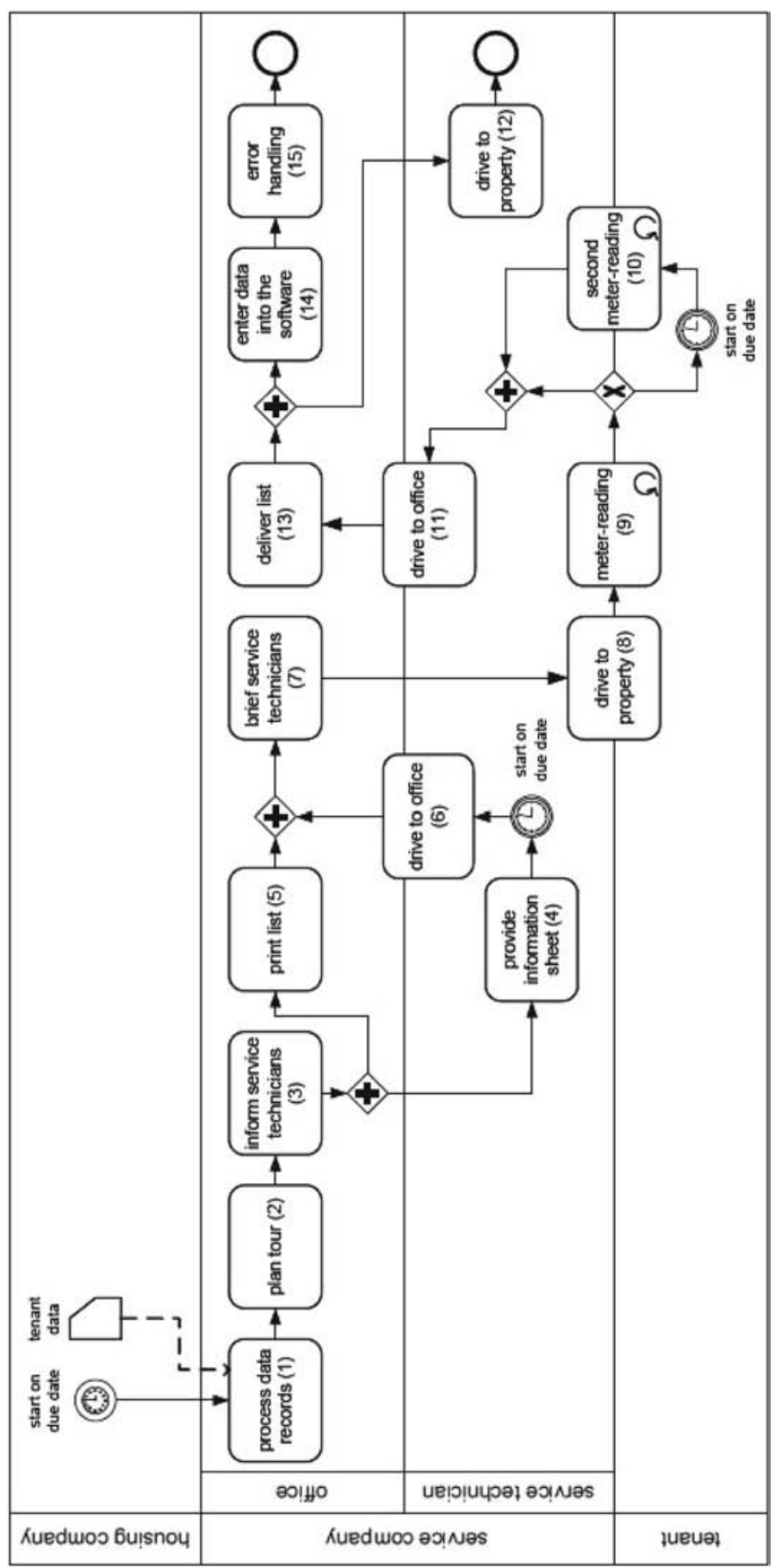

Modeling of mobile business processes

665

Figure 3. BPMN-diagramm of the recording of consumption values sub-process 
JEIM
20,6

\section{6}

apartment to apartment and manually records each value as well as the tenants name and the identification number of each device on his list. This activity takes approximately ten minutes per tenant. After recording, the service technician has to drive back to the office and deliver the recording lists. There the staff transcribes the data into the appropriate software.

\section{Identification of mobile processes}

Not every business process is suitable for an optimization by the use of mobile technology. Because of that, potentially mobile sub-processes need to be identified by means of different criteria. Therefore, our method provides an assessment scheme in order to evaluate each activity by different criteria. For the evaluation, a scale with values 0 (never true), 1 (frequently true), and 2 (always true) is used. The small scale limits the subjective discretion of the conducting person. The criteria can be divided into two different groups. The first group contains universal criteria showing general potential for optimization. They are creation of value, number of executions, importance for customer satisfaction and occurrence of media breaks. The second group of criteria allows to assess whether an activity is particularly influenced by the mobility of the process-executing person. The criteria are involved persons meet in specified location, involved persons are spatially separated, activity in motion and estimated amount of data. Table II shows the result of the evaluation of the process recording of consumption values using these criteria. The individual criteria were weighted by the housing company. Figure 4 shows the result of this analysis, which was conducted by a research associate from our university together with the company's' process supervisor. The activities meter-reading, second meter-reading, enter data into software and error handling are characterized by a particularly high potential for optimization. Interestingly, the general potential for optimization for these four activities is evenly distributed whereas the mobile potential for optimization causes differences in the evaluation. Furthermore, the activities inform service technician, brief service technician and deliver list are (almost) exclusively characterized by potential for optimization of the mobile criteria. On the basis of this analysis the development of a solution aiming at the activities with the biggest potential for optimization $(9,10,14$ and 15$)$ began. To do so, it is very important to interpret the term mobile potential in the right way. Activities with a high degree of mobile potential are characterized by the effects of physical mobility. This fact does not imply a need for implementing support for an activity by means of mobility-supporting technology. It is rather a question of examining the activities in the process context and justifying IT solutions for the whole process. Consequently, this can lead to a completely new structure of the activities. In particular, the IT solution should have positive effects on the four mentioned processes. The following section shows three alternative solutions which were developed on the basis of this analysis.

\section{Analyze mobile process}

Table III shows the distribution of the process costs over the single activities. The data was collected through a several days inspection of the process by a research associate from our university. He first acquired the process steps and then measured the average execution time for a single process step. The collected data was reviewed together with the company's supervisor of the process, who also defined the cost rates. The shown costs of the activities refer to the execution of the activity for one property. For this 


\section{Modeling of mobile business processes}

667
Table II. Evaluation of activities 


\section{JEIM \\ 20,6}

\section{8}

Figure 4.

Potential for optimization per activity

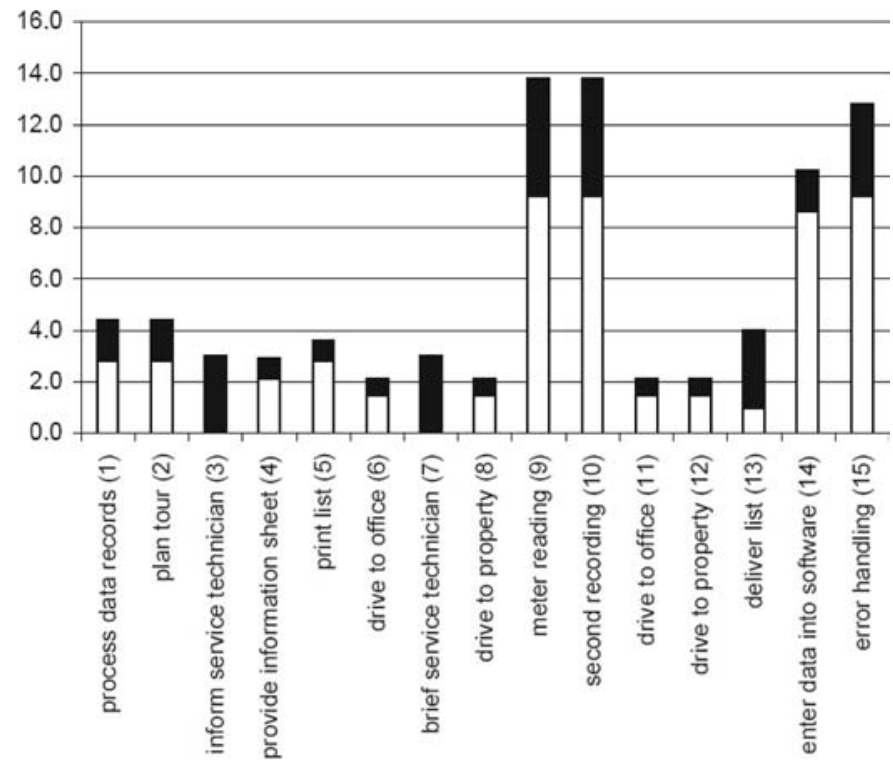

$\square$ General potential for optimization
Mobile potential for optimization

calculation, only personnel costs are considered. Therefore, an hourly rate of $€ 17.90$ was assumed. The whole personnel costs for the process recording of consumption values account for approximately $€ 55,500.00$.

Within the process, different shortcomings could be found. In approximately 10 percent of the cases, the tenant was absent, which leads to a repetition of the process starting with a new appointment. If the tenant is absent again, the process is repeated a third time at the tenant's own expense. Furthermore, there is the risk of transcription errors. They can be caused by inaccurate recordings or by accidentally mixing up the numbers. The service company estimates that approximately 5 percent of the recording lists are wrong, without anybody noticing it. Additionally, the staff estimates that around 10 percent of the lists are unreadable. In such cases, an inquiry by telephone and an adjustment are necessary. Apart from its vulnerability for errors, double recording attempts cause high costs. Because of the large number of apartments and the necessary personnel effort, the consumption values are recorded just once a year. Therefore, defective or manipulated meters can be identified only once a year.

\section{Developing alternative solutions and calculation of profitability}

The starting points for the development of a mobile solution are activities that involve meter-reading $(9,10)$. Therefore, an electronic recording seems to be an opportunity in order to avoid media breaks. It can be done either automatically or manually with the help of the process-executing person. The two propositions, online device support and mobile device support, are aiming to support the mobility of the service technicians. In 


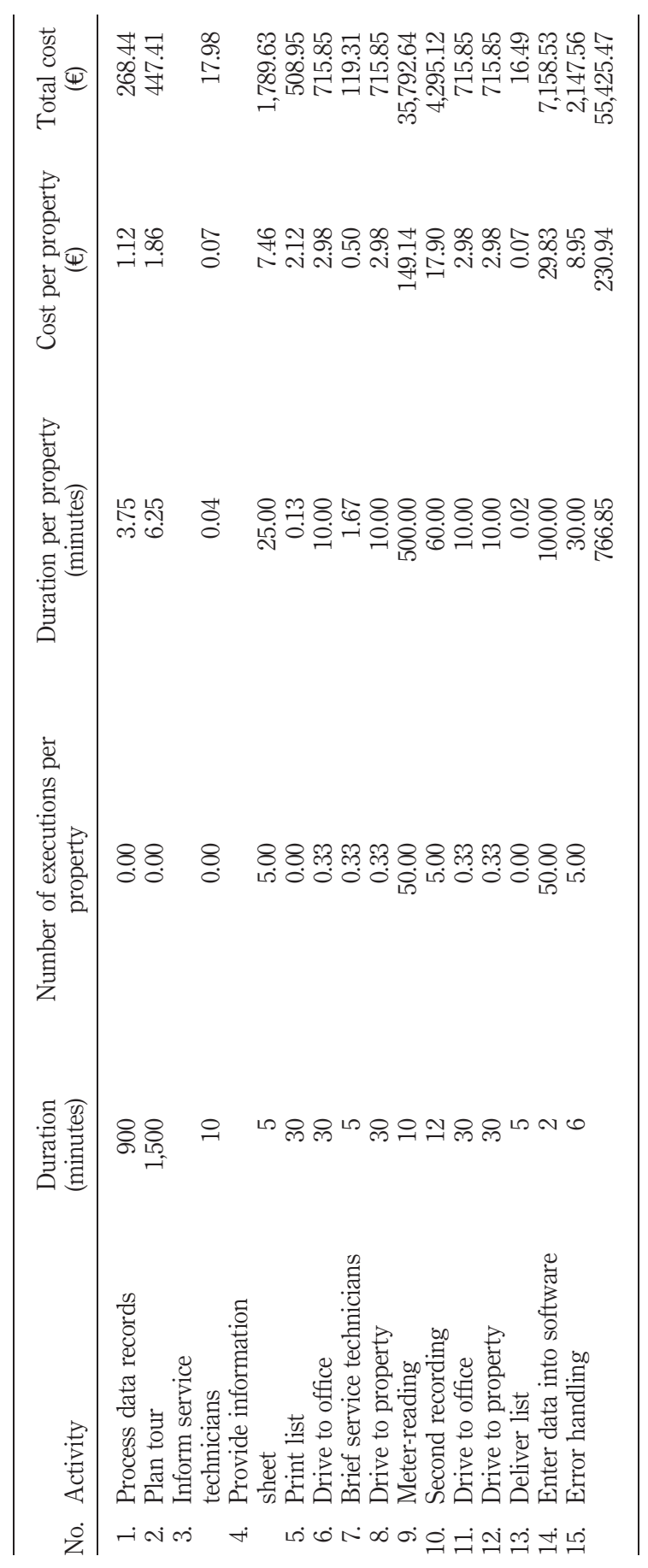

Table III. Cost of the sub-process recording of consumption values 
JEIM

20,6

\section{0}

contrast, the proposition remote meter-reading focuses on the removal of the mobile activities.

\section{Solution A: online device support}

One approach for the solution of the outlined problems is the use of a mobile electronic device. It displays an electronic form where the service technician can enter the consumption values. Using a cellular network adapter, the connection to a central server can be realized. The application can be designed browser-based due to its low complexity. In case the cellular network is not available, the consumption values can be noted on paper and transcribed later. Figure 5 shows the change in the sub-process that results from the implementation of this solution. The gray activities are the ones that are dropped compared to the original solution (see Figure 3). With this solution, the sub-process would be much shorter and simpler in structure than before, and especially the media breaks between meter-reading and transcription into the software can be avoided.

Furthermore, activities dealing with creation, transport and analysis of the recording lists are avoided. This affects activities 5, 6, 7, 11, 12, 13, 14 and 15 . As the service technician is always online with this solution, the use of the mobile device for other purposes is also possible. For example, support of the sub-process maintenance is conceivable. In the current situation the service technician receives calls on his mobile phone from the office to be informed about malfunctions at tenants' apartments. The distribution and management of these tasks by the use of mobile devices is an interesting opportunity that could be hooked on to the solution online device support.

The estimated costs for the new process according to the scheme shown in Table III amount to $€ 45,000.00$ per year, with only personnel and mobile communications costs were taken into account. This way, savings of approximately $€ 10,000.00$ a year can be realized. In order to implement this solution, a one-time investment of about $€ 40,000.00$ is needed. Thus, the project would reach its break-even about four years after its introduction. The essential advantages of this solution are:

- improvement of those activities with the highest potential for optimization;

- avoidance of media breaks between service technician and office;

- reduction of driving times;

- avoidance of handling recording lists; and

- creation of a framework for the development of further applications which can support the service technician via the mobile device.

Disadvantages of this solution are:

- in some cases, the application might not be available if the cellular network is out of reach;

- potential new sources for errors due to mistakes in handling the device or the software; and

- potentially higher risk of process disruption due to failure of the devices or the software.

Solution B: mobile device support

In contrast, an alternative to the solution outlined above could be to refrain from the use of a cellular network. Then, software needs to be installed on the mobile device in 


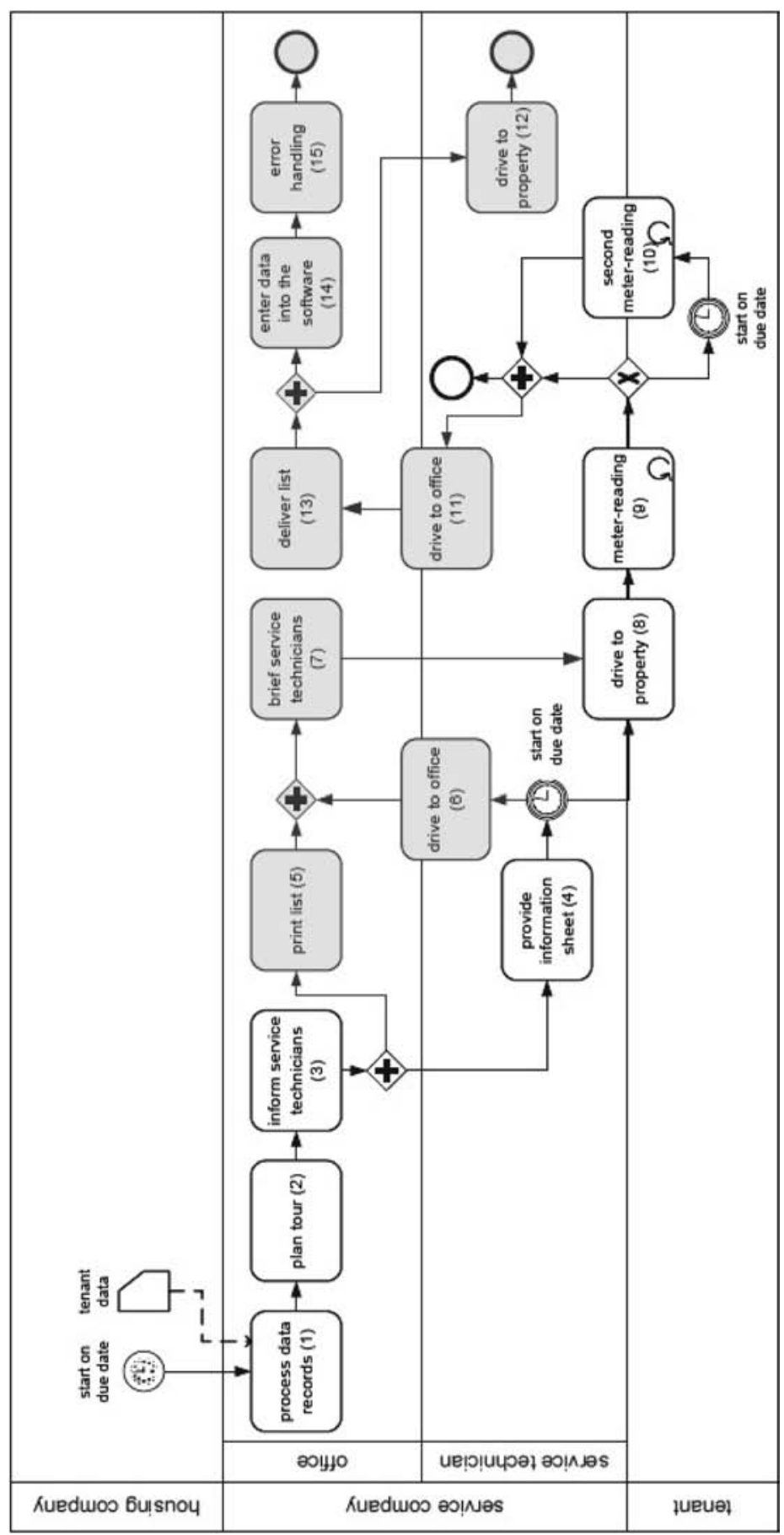

Modeling of mobile business processes

671

Figure 5. Recording of consumption values with online device support 
JEIM

20,6

672

order to support the meter-reading. The recorded consumption values are entered into the software by the service technician and later synchronized with the central server. In this case, the flow of the business process recording of consumption values also occurs as shown in Figure 5. However, the activity meter-reading, the synchronization with the central server must be conducted additionally, using a docking station in a determined location (e.g. the service technician's home, or office of the company).

Because no mobile network costs occur in this solution, the costs per year for the whole process amount to approximately $€ 40,000.00$ (personnel costs). This results in costs savings of about $€ 15,000.00$ a year compared to the original situation. To realize this solution, an investment of approximately $€ 40,000.00$ is needed. The project would turn worthwhile after three years. The financial savings are assessed as minor ones, but they are even higher than in solution A described above.

The advantages of this solution are the same as in the solution online device support. An additional advantage is the independence of radio networks, especially in basements and garages. Beyond, there are no cellular communication costs. The disadvantages of this solution are the same as for the one described above.

\section{Solution C: remote meter-reading}

A further alternative is the use of an automatic meter-reading system. For this, a device is needed which can be attached to the meter and which has the capability to record the meter-value and to send it via a wireless network to a central module in each apartment which sends the acquired data to a central server via a cellular network.

With this alternative, the business process recording of consumption values becomes unnecessary because no human intervention is required except in the case of a malfunction. Beyond, the consumption values can be recorded as often as desired. The exact estimation of costs for this was not possible in this project. There are a wide variety of vendors offering suitable devices for the creation of an infrastructure for remote meter-reading. The replacement of all meters would need an investment of millions of euros. Thus, the realization of this solution only makes sense in combination with the renovation or the new building of houses. Furthermore, prices for the needed devices are anticipated to be on the decrease for the next two years. Hence, an investment at this juncture does not seem recommendable. Thus, from the economical point of view, this alternative does not contribute to the primary goal of cost-savings. Nevertheless, the advantages of such a solution should be named. They are:

- complete avoidance of the business process recording of consumption values;

- considerable saving of personnel costs;

- complete avoidance of the afore mentioned sources of errors and media breaks;

- meter-reading at any desired time and frequency (enabling more detailed billing and forecasts); and

- early recognition of malfunctions at the meter (energy loss caused by malfunctions and theft can be avoided).

Disadvantages of the solution are the very high hardware investment needed and additional effort for the maintenance of the devices. 
Deducing requirements specifications

On the basis of our results, the company decided to realize the solution online device support. The determining factors were the cost savings per year as well as the opportunities for deploying further applications on the basis of the infrastructure of mobile devices and cellular networks. On the basis of the professional requirements, a requirements specification could be deduced. At this point, the question whether new software development is necessary or if single components or complete products from specialized vendors can be used was consciously left open. The draft of the system architecture is shown in Figure 6: the service technician is equipped with a mobile device. Using this, he can access the mobile application hosted by a service provider. The service company is connected via WAN to the service provider. The office can access all data via the intranet and its ERP client. The mobile application needs to allow the creation of recording lists and tour plans, the inquiry of the current state of recording at the office, and the display of recording lists and tour plans as well as the recording of the consumption values for each apartment for the service technician. The mobile device needs to fulfill special requirements of the service technicians:

- weight at maximum 500 gram;

- size at maximum (w/h/d) 90/200/50 mm;

- precipitation protection at minimum $100 \mathrm{~cm}$;

- display size at minimum 320/240 pt (colored);

- slightly water resistant;

- battery runtime at minimum 8 hours;

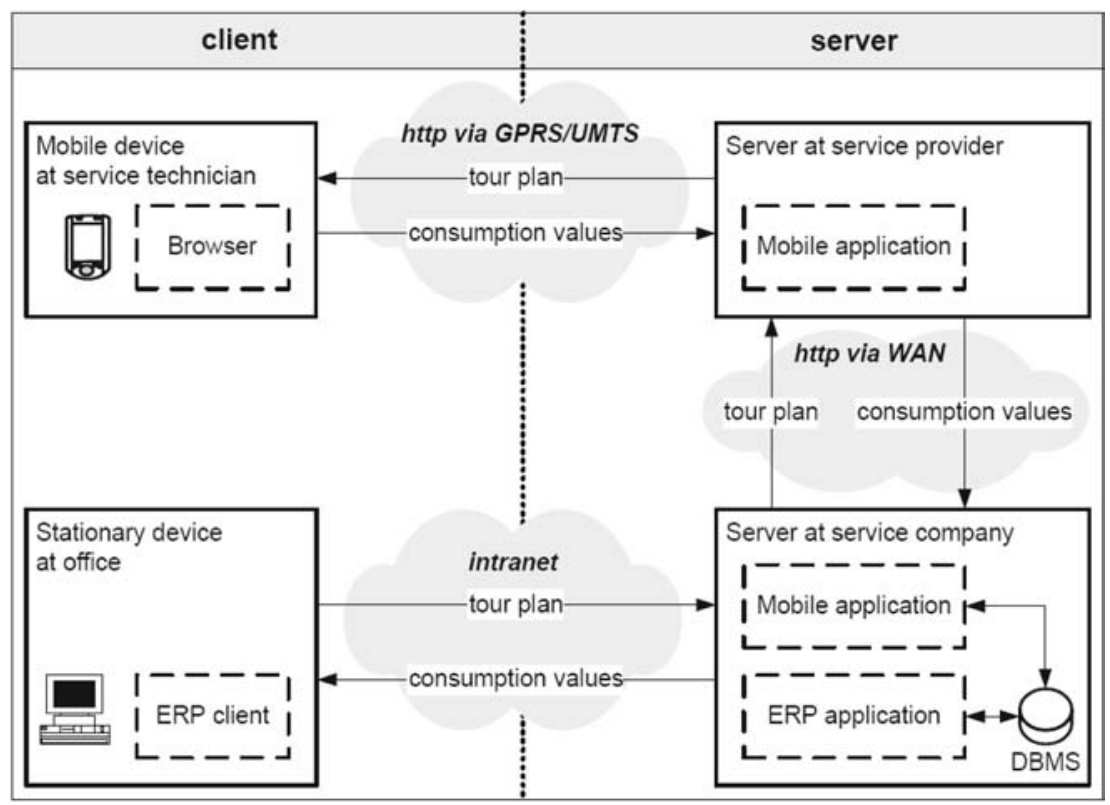

Modeling of mobile business

processes

673

Figure 6.

System architecture for solution online device support 
JEIM
20,6

674

- docking station with car recharge adapter; and

- large keypad with separate number field.

\section{Synthesis}

With the method shown above we proposed a procedure for choosing a suitable mobile solution for achieving savings from reduced process costs that are as high as possible and exceed the initial investment after a certain period of time. We showed how to obtain predictions for costs and benefits for a mobile IT solution, in particular how to conduct a process analysis for the current process. Furthermore, we showed how to calculate execution costs of the target process, how to develop different mobile IT solutions and how to conduct an ROI analysis for the target scenarios.

The proposed method is therewith a contribution for decreasing the lack of methodology describing the planning and the design of a mobile IT solution from a business analysis point-of-view. The development of an IT solution for mobile business processes requires a detailed analysis of the business requirements as well as an adaptation of the solution onto these requirements. With the case study, it was shown that the described method can help to accomplish the outlined tasks. The main feature of the method is the analysis of the business processes, as well as their dependencies. Furthermore, the mobile solutions can be evaluated economically in order to justify the needed investment. If the decision for the realization of an alternative solution is made, comprehensive defaults for the system development can be defined on the basis of the detailed business process analysis.

\section{Conclusion}

During the case study, we ascertained several points about how companies act when thinking about the introduction of mobile solutions. In the following, we discuss these issues with respect to the aim of our method and to the literature review given above.

- The company usually knows exactly which processes are insufficiently organized and where a mobile solution could be useful. This is in line with the reportings of May et al. (2005), Bowden et al. (2004) and Kavakli and Loucopoulos (1998). Thus, an explicit discovery of mobile processes is not needed. However, the individual activities in a mobile process need to be evaluated in terms of their mobility, costs and optimization potential. Therefore, the process mapping technique from our method worked quite well when discussing the activities which should be addressed by a mobile solution with the company's executives.

- The main question to be answered from the company's point-of-view is if the investment needed for the mobile solution can be justified through the expected savings over a certain period of time. Thus, a quantitative process analysis as shown above is essential. In order to improve the benefit of the mobile solution, the framework described in Nah et al. (2005) could be used. For calculating the ROI, the consideration of personnel costs usually is sufficient. All direct benefits of the use of mobile technology (avoidance of media breaks, just-in-time data supply, coordination etc.) lead indirectly to a shortening of processing times and thereby to decreasing personnel costs.

- Always-online architectures offer the most advantages, but their reliability suffers from todays' varying cellular network coverage and the low bandwidth. Hybrid architectures allow for temporary offline work and therefore seem to be 
better qualified for todays' use in most of the cases. This matches with the results shown in Sairamesh et al. (2004) and Dustdar and Gall (2003).

- Introducing a mobile solution requires setting up a proper technical infrastructure. This infrastructure could often be used to support other processes of mobile workers, too. The required investment for establishing that infrastructure is often just compared with the savings from the change regarding the original process. This is understandable because the urgency and benefit of changes is different from process to process, different people are responsible for different processes, and budgets are low. Nevertheless, this may lead to a situation where a mobile solution is evaluated as too expensive for an isolated process, although it would be profitable when using the technical infrastructure for another process to obtain additional savings there. When conducting an economic evaluation of such investment projects, future options should be strongly considered. A systematical approach to this is the future option theory (see, e.g. Li and Johnson, 2003; Kumar, 2002).

Based on the shown method, further research is planned in order to improve the method. Firstly, existing languages for modeling and analyzing mobile business processes seem unsuitable for the explicit modeling of mobility. In order to use the process model for the prediction of efficiency and performance of the solution, a simulation of the transferred data volume as well as the expected response time is needed. Secondly, the systematic deduction of general conditions for the system architecture of a mobile system from the process model would be desirable. Therefore, patterns for mobile business processes as well as corresponding classes of mobile system architectures could be helpful.

\section{References}

Bowden, S., Dorr, A., Thorpe, A. and Anumba, C.J. (2004), "Mapping site processes for the introduction of mobile IT", in ECPPM '04: eWork and eBusiness in Architecture, Engineering and Construction, A.A. Balkema Publishers, Lisse, pp. 491-8.

Churchill, E.F. and Munro, A.J. (2001), "Work/place: mobile technologies and arenas of activity", SIGGROUP Bulletin, Vol. 22, pp. 3-9.

Dix, A., Rodden, T., Davies, N., Trevor, J., Friday, A. and Palfreyman, K. (2000), "Exploiting space and location as a design framework for interactive mobile systems", $A C M$ Transactions on Computer-Human Interaction, Vol. 7, pp. 285-321.

Dustdar, S. and Gall, H. (2003), "Architectural concerns in distributed and mobile collaborative systems", Journal of Systems Architecture, Vol. 49, pp. 457-73.

Heemstra, F.J. and Kusters, R.J. (2004), "Defining ICT proposals", Journal of Enterprise Information Management, Vol. 17 No. 4, pp. 258-68.

Kakihara, M. and Sorensen, C. (2001), "Expanding the 'mobility' concept”, SIGGROUP Bulletin, Vol. 22, pp. 33-7.

Kavakli, E.V. and Loucopoulos, P. (1998), "Goal-driven business process analysis - application in electricity deregulation", in CAiSE '98: Proceedings of the 10th International Conference on Advanced Information Systems Engineering, Springer-Verlag, London, pp. 305-24.

Kleist, V.F. (2003), “An approach to evaluating e-business information systems projects”, Information Systems Frontiers, Vol. 5 No. 3, pp. 249-63.

Kohli, R., Sherer, S.A. and Baron, A. (2003), "IT investment payoff in e-business environments: research issues", Information Systems Frontiers, Vol. 5 No. 3, pp. 239-47.

\section{Modeling of mobile business \\ processes}

675 
JEIM

20,6

676
Kumar, R.L. (2002), "Managing risks in IT projects: an options perspective", Information and Management, Vol. 40, pp. 63-74.

Leem, C.S., Yoon, C.Y. and Park, S.K. (2004), "A process-centered IT ROI analysis with a case study”, Information Systems Frontiers, Vol. 6 No. 4, pp. 369-83.

Li, X. and Johnson, J.D. (2003), "The value of managerial flexibility in strategic IT investment: identify the real options of resource allocation", Advanced Topics in Information Resources Management, Idea Group Publishing, Hershey, PA, pp. 111-32.

May, A., Mitchell, V., Bowden, S. and Thorpe, T. (2005), "Opportunities and challenges for location aware computing in the construction industry", MobileHCI '05: Proceedings of the 7th International Conference on Human Computer Interaction with Mobile Devices and Services, ACM Press, New York, NY, pp. 255-8.

Nah, F.F.H., Siau, K. and Sheng, H. (2005), "The value of mobile applications: a utility company study", Communications of the ACM, Vol. 48, pp. 85-90.

Perry, M., O’Hara, K., Sellen, A., Brown, B. and Harper, R. (2001), "Dealing with mobility: understanding access anytime, anywhere", ACM Transactions on Computer-Human Interaction, Vol. 8, pp. 323-47.

Pica, D., Sorensen, C. and Allen, D. (2004), "On mobility and context of work: exploring mobile police work", HICSS '04: Proceedings of the Proceedings of the 37th Annual Hawaii International Conference on System Sciences (HICSS'04) - Track 3, IEEE Computer Society, Washington, DC, p. 30081.3.

Roman, G.-C., Picco, G.P. and Murphy, A.L. (2000), "Software engineering for mobility: a roadmap", pp. 241-58, in ICSE '00: Proceedings of the Conference on The Future of Software Engineering, ACM Press, New York, NY.

Sairamesh, J., Goh, S., Stanoi, I., Padmanabhan, S. and Li, C.S. (2004), "Disconnected processes, mechanisms and architecture for mobile e-business", Mobile Networks and Applications, Vol. 9, pp. 651-62.

Saleh, Y. and Alshawi, M. (2005), "An alternative model for measuring the success of IS projects: the GPIS model”, Journal of Enterprise Information Management, Vol. 18 No. 1, pp. 47-63.

Thai, B., Wan, R., Seneviratne, A. and Rakotoarivelo, T. (2003), "Integrated personal mobility architecture: a complete personal mobility solution", Mobile Networks and Applications, Vol. 8, pp. 27-36.

van der Heijden, H. and Valiente, P. (2002), "The value of mobility for business process performance: evidence from Sweden and The Netherlands", in ECIS '02: Proceedings of the European Conference on Information Systems.

Wang, Y., van de Kar, E. and Meijer, G. (2005), "Designing mobile solutions for mobile workers: lessons learned from a case study", pp. 582-9, in ICEC '05: Proceedings of the 7th International Conference on Electronic Commerce, ACM Press, New York, NY.

White, S. (2003), "Business process modeling notation", available at: www.BPMI.org

\section{Corresponding author}

A. Köhler can be contacted at: koehler@ebus.informatik.uni-leipzig.de

To purchase reprints of this article please e-mail: reprints@emeraldinsight.com Or visit our web site for further details: www.emeraldinsight.com/reprints 